Many faculties are vigorously discussing these questions now.

Nearly all the proposals in what is a useful and provocative little booklet mean greater expenditure. We must hope that those who hold the purse-strings will realize that to-day the universities are a long way behind scratch. The greater part of the first increases of grant will be expended in bringing us back into line for a good start after the backsliding made inevitable by six years of war.

It has been difficult to review the report issued by the National Union of Students in a short article : it is quite impossible to do justice to the many subjects touched upon at the Second Educational Conference of the Association of Allied Professors and Lecturers, held in London on April 14, 1944, the proceedings of which are now available*. Mental indigestion and a seething mind are inescapable after a first reading. There are, however, some impressions that pick themselves out. The modern Soviet university seems to have got farthest from the 'ivory tower' idea, but this has been incidental to profound social and political changes. Unless we are prepared to follow them in the larger field - and I for one think that we should lose more than we should gain by doing sowe must seek to attain the same end by more devious ways. The United States are trying hard to achieve an educated democracy and have had a measure of success. It has been easier in a country with an expanding frontier than it has been in overcrowded Western Europe with its bounds set by history and tradition. It will be less easy in the America of the future, when the expanding frontier will be a memory of the past. When I visited the United States in 1936, the Federal Government was spending sixty million dollars a year on student maintenance, because it was becoming progressively more difficult to work one's way through college in competition with the regular labour force.

I like Sir Fred Clarke's definition of training as "the cutting edge that makes education specifically serviceable". General acceptance might give the word and idea a new lease of respectable and useful life. Interchange on the Francqui chair scale, with its fully equipped laboratory and specialist assistants for the visiting professor, approaches the ideal, and is linked in my mind with the good idea of occasional interchange between the professor and master of the school sixth form. The greatest professors like taking elementary classes despite what Bruce Truscott says. It is not too great a step to go back to school, though the step would certainly be new. The American system of sabbatical leave and the junior's wanderjahr have done much for peaceful penetration into China, and the British Commonwealth might well emulate their trans-Atlantic cousins here. Of the great university dangers, 'specialization, mechanization of learning, and interference by the State', we in Britain know something of the first two, but we have steered clear of the third thanks to our genius for anomalies in our government set-up. Long may that remain true.

Sir Ernest Barker has likened the ancient universities to mountains of ice nine-tenths submerged in seas of history and tradition. Having had experience or Antarctic exploration, I am tempted to carry the analogy a step further. The new universities are more like the snowbergs from the Antarctic continent with half their bulk above water. They may have a more workmanlike façade, if a different one. They are without the peaks and pinnacles, but there is something to be said for a solid rectangular shape. They are mcre responsive to the winds of public opinion. They are more readily adaptable to the social environment in which they are set. These are, on balance, not bad characteristics. I will not press the analogy too far, for icebergs and snowbergs alike, when they grow older, pass through the stage of being hidden dangers to navigation, and finally they disappear leaving no trace.

* Association of University Professors and Lecturers of the Allied Countries in Great Britain. Second Education Conference, April 15, 1944 : Some Comparisons between Universities. Pp. xvi +64. (Oxford: Basil Blackwell, 1944.) 2s. 6d. net.

\title{
NEW FELLOWS OF THE ROYAL SOCIETY
}

THE following were elected fellows of the Royal Society on March 14 :

Mr. L. Colebrook, a member of the scientific staff of the Medical Research Council. Distinguished in the application of bacteriology to clinical medicine, he played a leading part in the practical establishment of the 'sulpha' drugs, and has thrown much light on the fevers of childbirth. During the War he has directed important investigations on burns.

Mr. W. S. FARREN, aeronautical engineer, director of the Royal Aircraft Establishment, Farnborough. $\mathrm{He}$ has been associated with aeronautical research and development continuously since 1914, and has contributed greatly to advances in the science and pracetice of aeronautics.

Dr. N. Feather, lecturer in physies in the University of Cambridge; distinguished for investigations which have added much to knowledge of the spontaneous and induced disintegrations of atomic nuclei.

Prof. J. H. Gaddum, professor of pharmacology in the University of Edinburgh ; distinguished for his work on the identification and estimation of acetyl- choline, adrenaline and histamine in animal tissues and for his experimental contributions to the conception of cholinergic and adrenergic nerves.

DR. H. Godwin, lecturer in botany in the University of Cambridge; distinguished as a plant ecologist, and especially for his contributions to the knowledge of the post-glacial history of British vegetation based on the pollen analysis of recent deposits.

Prof. J. M. Gulland, Sir Jesse Boot professor of chemistry, University College, Nottingham; distinguished for his analytical and synthetic work in the phenanthrene group of alkaloids, and for his work in the development of the chemistry of substances of biological importance.

Mr. H. W. Harvey, marine biologist; distinguished for his contributions to our knowledge of the 'productivity of the sea' by co-ordinating the varied factors, physical, chemical and biological, which determine it.

Prof. V. C. Illing, professor of oil technology in the Imperial College of Science and Technology; distinguished for his researches on the relation of texture of sediments to oil accumulation, and for 
refinements of stratigraphical and geophysical methods applied to interpret the structure of oilbearing lands.

Mr. A. E. Ingham, University lecturer in mathematics in the University of Cambridge ; distinguished for his researches in pure mathematics, particularly in the theory of numbers.

Prof. H. D. KAY, director of the National Institute for Research in Dairying ; distinguished for his biochemical work, particularly for his investigations upon organic phosphorus compounds and the phosphatases. Recently he has applied his methods to the practical problems of dairying.

DR. W. B. Lewrs, lecturer in physics in the University of Cambridge; distinguished both for his contributions to the investigation of the structure of atomic nuclei and also to the development of the science of electronics, with special relation to ultrahigh frequency radiation.

Dr. Kathleen Lonsdale, physicist, Royal Institution; distinguished for outstanding contributions to the investigation of the crystalline structure of organic compounds by means of X-ray analysis. Particularly important have been her recent researches into the fundamental mechanics of crystal structure.

Prof. P. C. Manalanobis, professor of physics, Presidency College, Calcutta, and founder of the Statistical Laboratory, Calcutta; distinguished for his contributions both to statistical theory and to the applications of statistics, particularly to sample surveys, agriculture and population.

Prof. R. E. Pererls, professor of applied mathematics in the University of Birmingham; distinguished for his contributions to theoretical physics, particularly in the application of quantum mechanics to the electron theory of metals and other phenomena of the solid state, and in the theory of the atomic nucleus.
Prof. J. Monteath Robertson, Gardiner professor of chemistry in the University of Glasgow ; distinguished for his work on crystal structure by the methods of X-ray analysis. He has made measurements of great accuracy in this field, and has derived from them precise molecular structures, electron density distributions, and inter-atomic distances of organic molecules.

Prof. F. M. Rowe, professor of colour chemistry and dyeing in the University of Leeds. As leading. dyestuff technologist, his work has been of national importance. He has made varied and original contributions to the chemistry of dyes and intermediates.

Sir WILLIAM Wright SMITH, King's botanist in Scotland, regius keeper of the Royal Botanic Garden, Edinburgh, and regius keeper of botany in the University of Edinburgh ; distinguished for his contributions to the taxonomy of Angiosperms, and especially for his monographic treatment of the genera Primula and Rhododendron.

Marjory Stephenson, a member of the scientific staff of the Medical Researeh Council ; distinguished for her biochemical researches upon the metabolism of bacteria, which, with those of her pupils during twenty-five years, have included work upon hydrogenase, lactic dehydrogenase and adaptive enzymes.

Mr. B. N. WALLIS, mechanical engineer, chief of research and development of Vickers-Armstrong Ltd., Aircraft Section. He has been responsible for many new projects of design, and his work has led to secret developments which have been of great importance in the war effort.

Mr. F. Z. Youn, lecturer in zoology in the University of Oxford; distinguished for his outstanding contributions to knowledge of the nerve fibre, both of its structure and function. During the War he has worked on important clinical aspects of the repair of damaged nerves.

\section{NEWS and VIEWS}

\section{Prof. Guido Castelnuovo}

Mathematicians will be pleased to learn that Prof. Guido Castelnuovo, formerly professor of geometry in the University of Rome, is safe and well. In a recent letter to Mr. L. Roth, of the Imperial College of Science and Technology, London, he relates that he, with members of his family, obtained refuge during the German occupation of Rome, and that he has now returned to his well-known house in the Via Boncompagni. Castelnuovo is eighty years old this year; the world of science will unite in congratulation. Castelnuovo's work (which was reviewed in Nature of December 10, 1938, p. 1016) represents the best in Italian geometrical thought over a long period. Born in an age which, to quote his own phrase, "closed one epoch and opened another", his first papers were, naturally enough, on the projective geometry of higher space. But soon, with Corrado Segre, he was making essential contributions to the algebraic geometry of curves which, sixty years ago, was beginning to assume its modern form. Then, in 1894, with Federigo Enriques as his collaborator, he initiated the study of the algebraic geometry of surfaces, on no firmer a foundation than the hints and conjectures (some of them mistaken) of Max Noether. Much of this work is definitive, in a negative as well as in a positive sense; for where he has paused, his successors in the field have often found it impossible to progress. Perhaps the most celebrated of Castelnuovo's papers is the memoir of 1896 , in which he gives necessary and sufficient conditions for the rationality of a surface, that is, for the existence of a one-toone algebraic correspondence between the points of the surface and those of a plane. Incidentally, this was quite literally a piece of research, in that the author did not suspect what the conditions were before he began to write the paper. So the theory of rational surfaces was able to take its place by the side of the classical theory of rational curves.

Already (and, in fact, during the previous ten years), Italian geometers were posing similar questions for the threefold, that is, the locus which is represented analytically by an equation in four co-ordinates. The quadric threefold, like the quadric surface, is easily seen to be rational by projecting the locus from a point of itself. It was also well known (though the proof is less obvious) that the general cubic surface is rational. The question now arose, what could be said about the general cubic threefold ? The question was destined to become one of the historic problems of geometry. At first glance one could see that the answer would either be imme- 